\title{
Influence Mechanism of Nitrogen Injection Into Closed Fire Zone On the Re-Ignition For Residual Coal in Goaf
}

\author{
Yong-liang XU \\ Henan Polytechnic University \\ Zejian LIU \\ Henan Polytechnic University \\ Xing-lin WEN \\ Henan Polytechnic University \\ Lan-yun Wang ( $\square$ lanyun.wang@gmail.com ) \\ Henan Polytechnic University \\ Zhi-guang LV \\ Henan Polytechnic University \\ Jin-dong WU \\ Henan Polytechnic University \\ Min-jie LI \\ Henan Polytechnic University
}

\section{S.I. : Control of Coal Fire}

Keywords: Coal re-ignition, Unsealed fire zone, Uniaxial stress, Thermal effect, Re-ignition mechanism

Posted Date: October 18th, 2021

DOl: https://doi.org/10.21203/rs.3.rs-958957/v1

License: (c) (1) This work is licensed under a Creative Commons Attribution 4.0 International License. Read Full License 


\section{Influence Mechanism of Nitrogen Injection into Closed Fire} Zone on the Re-ignition for Residual Coal in Goaf

Yong-liang XUa,b,c,1, Ze-jian LIU, ${ }^{a, 1}$, Xing-lin WENª, Lan-yun WANG ${ }^{a, b, c *}$, Zhi-guang LVª, Jin-dong WUa, Min-jie $\mathrm{LI}^{\mathrm{a}}$

${ }^{a}$ School of Safety Science and Engineering, Henan Polytechnic University (HPU), Jiaozuo 454003, China;

bState Key Laboratory Cultivation Base for Gas Geology \& Gas Control of HPU, Jiaozuo 454003, China; ${ }^{c}$ Collaborative Innovation Center for Coal Safety Production \& High-Efficient-Clean Utilization, Jiaozuo 454003, China

ABSTRACT: Coal is the foundation of Chinese energy and economic structure, and the unsealing of coal mine fires would cause a great risk of coal re-ignition. The uniaxial compression equipped with a temperature-programmed (UCTP) device was built to explore the influence of pressure-bearing state on the re-ignition characteristics of residual coal. The Scanning Electron Microscope (SEM), Synchronous Thermal Analyzer (STA) and Fourier Transform Infrared Absorption Spectrometer (FTIR) was applied to investigate the microscopic structure and thermal effect of the coal samples. Moreover, the microscopic effect of uniaxial stress on coal re-ignition was revealed, and the re-ignition mechanism was also obtained. As the uniaxial stress increases, the number, depth and length of the fractures in the pretreated coal increase, and the filling material increases. The application of uniaxial stress causes the thermal conductivity to change periodically, which enhances the heat transfer inhibition effect of nitrogen and prolongs the oxidation exothermic stage. The content of oxygen-containing functional groups has a high correlation with apparent activation energy, and coal samples at $6 \mathrm{MPa}$ are more likely to re-ignition when the fire zone is unsealed. Uniaxial stress controls the re-ignition mechanism by changing the structure of fractures and pores. The side chains and functional groups in the coal structure are easier to break under thermal-stress coupling. The higher the $\cdot \mathrm{OH}$ content, the more difficult it is to re-ignition. The research results have laid a solid theoretical foundation for the safe unsealing of coal field fire areas, tightened the common bond between the actual industry and the experimental theory in the closed fire area, and provided theoretical guidance for preventing coal re-

\footnotetext{
${ }^{1}$ Co-first author: These authors contributed equally to this work.
}

*Corresponding author at: School of Safety Science and Engineering, Henan Polytechnic University, Jiaozuo 454003, China.

E-mail address: lanyun.wang@gmail.com (L., Wang). 
ignition.

KEYWORDS: Coal re-ignition, Unsealed fire zone, Uniaxial stress, Thermal effect, Re-ignition mechanism

\begin{tabular}{|c|c|c|c|}
\hline \multicolumn{4}{|c|}{ lature } \\
\hline$W$ & $\begin{array}{l}\text { The relative content of functional } \\
\text { groups, } \%\end{array}$ & $C_{O_{2}}^{0}$ & $\begin{array}{l}\text { The oxygen concentration at the inlet, } \\
\mathrm{mol} \cdot \mathrm{cm}^{-3}\end{array}$ \\
\hline$A_{i}$ & Functional group area & $C_{O_{2}}^{L}$ & $\begin{array}{l}\text { The oxygen concentration at the outlet, } \\
\mathrm{mol} \cdot \mathrm{cm}^{-3}\end{array}$ \\
\hline$f_{i}$ & $\begin{array}{l}\text { Vibration strength of the functional } \\
\text { group }\end{array}$ & $E_{a}$ & Apparent activation energy, $\mathrm{J} \cdot \mathrm{mol}^{-1}$ \\
\hline$\varepsilon$ & the uniaxial strain & $\theta$ & $\begin{array}{l}\text { the core temperature of the coal } \\
\text { sample, }{ }^{\circ} \mathrm{C}\end{array}$ \\
\hline$\Delta h$ & nt of deformation, $\mathrm{m}$ & $A_{0}$ & Pre-exponential factors, $\mathrm{s}^{-1}$ \\
\hline$h_{0}$ & he coal sample filled & $Q$ & The flow rate of the supplied air, $\mathrm{mol} \cdot \mathrm{s}^{-1}$ \\
\hline$\varphi_{0}$ & the initial void ratio & $C_{e}$ & the heat capacity, $\mathrm{J} \cdot(\mathrm{kg} \cdot \mathrm{K})^{-1}$ \\
\hline$\varphi$ & $\begin{array}{l}\text { f a broken coal sample } \\
\text { strain }\end{array}$ & $\lambda$ & the thermal conductivity, $\mathrm{W} \cdot \mathrm{m}^{-2} \cdot \mathrm{K}^{-1}$ \\
\hline$d$ & the inner diameter of the reactor, $m$ & $\Delta X$ & $\begin{array}{l}\text { the distance between the core } \\
\text { temperature and the wall of the reactor, } m\end{array}$ \\
\hline$m$ & the mass of the coal sample, $\mathrm{kg}$ & $T_{O V}$ & the control temperature of heating \\
\hline$\rho$ & the density of the coal sample, $1.4 \mathrm{~g} \cdot \mathrm{m}^{-3}$ & $T$ & $\begin{array}{l}\text { the core temperature of the coal sample, } \\
\mathrm{K}\end{array}$ \\
\hline
\end{tabular}

\section{Introduction}

Underground coal fires are mainly fires caused by the re-ignition of coal seams(Plakunov et al. 2020). The closed fire extinguishing method is the main measure to solve coal fire disasters in major coal producing countries such as Europe, Australia, China, and the United States (Zhou et al. 2009). However, when the unsealed fire zone reduces economic losses, the re-ignition of coal seriously threatens the safe production of coal mines. Because the leftover coal is subjected to the concentrated stress caused by the burning and collapse of the roof and the stratum collapse, it will affect the spontaneous combustion characteristics of the coal (Xu et al. 2021). Therefore, studying the oxidation mechanism of coal re-ignition and exploring the occurrence and oxidation characteristics of coal re-ignition after nitrogen injection are of great significance to the prevention and control of coal reignition. 
So far, the research on the re-ignition of coal when the fire zone is unsealed is mainly related to the disaster caused by gas explosion. Through numerical simulation software, scholars have obtained the gas explosion areas and locations that are most likely to be caused by coal re-ignition during unsealing, and determined the influence of atmospheric pressure on the interior of the fire area (Shi et al. 2017; Zhou et al. 2015; Duan et al. 2020; Duan et al. 2020). Numerical simulation methods provide a wealth of theoretical basis for areas that cannot be actually detected in the coal mine fire area. The experimental methods mainly focus on the oxidation and spontaneous combustion of the coal itself. However, the residual coal in the fire zone is mostly secondary oxidized coal. The researchers analyzed the production law of indicator gases, changes in absorbance, development trends of fire areas, methods of predicting coal re-ignition, and measures to reduce gas explosion disasters caused by re-ignition. (Lu et al. 2018; Tan et al. 2014; Zhou et al. 2010; Cheng et al. 2012; Cheng et al. 2013; Zheng et al. 2020; Shang et al. 2019). However, the residual coal in the goaf is a frequent place for re-ignition when the fire area is unsealed. The stress state of the residual coal and the tar produced by pyrolysis will cause changes in the spontaneous combustion of the coal (Chao et al. 2021; Hasan et al. 2015). Their research shows that the flow field and heat transfer during closed and unsealed coalfield fire areas are very important to the safety production and economic benefits of coal mines. The above research shows that it is feasible to analyze the molecular structure changes and heat and mass transfer during the coal re-ignition process from the perspective of numerical analysis, gas atmosphere, stress conditions, or micro-scale analysis.

Coal re-ignition is a complex physical and chemical reaction process involving the interaction and transformation of multiple chain reaction mechanisms. Therefore, it is difficult to reflect the state of the coal at the time of unsealing only by investigating its re-ignition characteristics of secondary oxidized coal. The redistribution of stress caused by coal and rock caving in the enclosed fire area, the state of the residual coal in the enclosed fire area under stress is irregular and 
inaccessible, resulting in a relatively limited understanding of the enclosed and unsealed fire areas. However, the re-ignition of coal during unsealing is closely related to its accumulation state and environmental conditions. During the occurrence and development of the re-ignition, the coal is in a broken state. After they undergo the action of the stress field, the flow field and the temperature field, the heat and mass transfer during the re-ignition have undergone major changes. Therefore, the fluid-solid-thermal-stress full coupling function of the UTCP device is used to better realize the pretreatment of coal. Combined with the synchronous thermal analyzer and the Fourier infrared spectrometer (FTIR), it reveals the microscopic characterization of the coal after re-ignition.

\section{Experimental materials and instruments}

\subsection{Coal samples}

The experimental coal samples were taken from the Liuhuanggou mining area in Xinjiang Province, where large-scale coal field fires had occurred in China. The coal type is long flame coal with low metamorphism. The fresh coal sample was wrapped with multi-layer plastic wrap. After being transported to the ground, the coal sample was put into the sample bag and filled with nitrogen. After the fresh coal sample arrived in the laboratory, the outer shell was stripped, and the internal coal sample was crushed and the coal sample with a particle size of 0.2-0.45 mm was selected. Quickly place the selected coal sample in a vacuum drying oven for 72 hours, and then squeeze out the air to seal for storage. Take the dried coal sample and grind it to obtain the industrial analysis and elemental analysis of the experimental sample, as shown in Table 1.

Table 1 Proximate and ultimate analysis of coal sample

\begin{tabular}{ccccccccc}
\hline \multicolumn{7}{c}{ Proximate analysis(W/\%) } & \multicolumn{7}{c}{ Ultimate analysis(W/\%) } \\
\hline $\mathrm{M}_{\mathrm{ad}}$ & $\mathrm{A}_{\mathrm{ad}}$ & $\mathrm{V}_{\mathrm{daf}}$ & $\mathrm{Fc}_{\mathrm{ad}}$ & $\mathrm{C}_{\mathrm{daf}}$ & $\mathrm{H}_{\mathrm{daf}}$ & $\mathrm{N}_{\mathrm{daf}}$ & $\mathrm{O}_{\text {daf }}^{*}$ & $\mathrm{~S}_{\mathrm{daf}}$ \\
6.43 & 15.71 & 32.32 & 45.54 & 70.86 & 5.44 & 0.69 & 7.81 & 0.37 \\
\hline
\end{tabular}

2.2 Experimental instrument 


\subsubsection{UCTP device}

Combined with the environment of the coal in the closed fire zone, the atmosphere environment of the experimental coal sample during the heating process should be the heating in a nitrogen environment. Using the self-built UCTP device, the axial stress test of broken coal can be carried out. After setting different axial loading intensities, the flow rate of different kinds of gases can be adjusted to pass into the reactor to perform heating-up oxidation experiment and percolation experiment. The reactor equipped with the device has a maximum height of $15 \mathrm{~cm}$ and a diameter of $10 \mathrm{~cm}$. It is surrounded by a heating jacket that can control the heating rate. The maximum temperature of the device can be from room temperature to $450{ }^{\circ} \mathrm{C}$. Simultaneously, the upper cover is equipped with a temperature probe to measure the core temperature of the coal sample. The accuracy of uniaxial stress is $0.1 \mathrm{MPa}$, the accuracy of gas pressure is $0.01 \mathrm{MPa}$, and the flow accuracy can reach $0.001 \mathrm{~L} \cdot \mathrm{min}^{-1}$. The air inlet pipeline passes through the reaction kettle after winding the heating jacket several times, and an air outlet is provided under the reaction kettle.

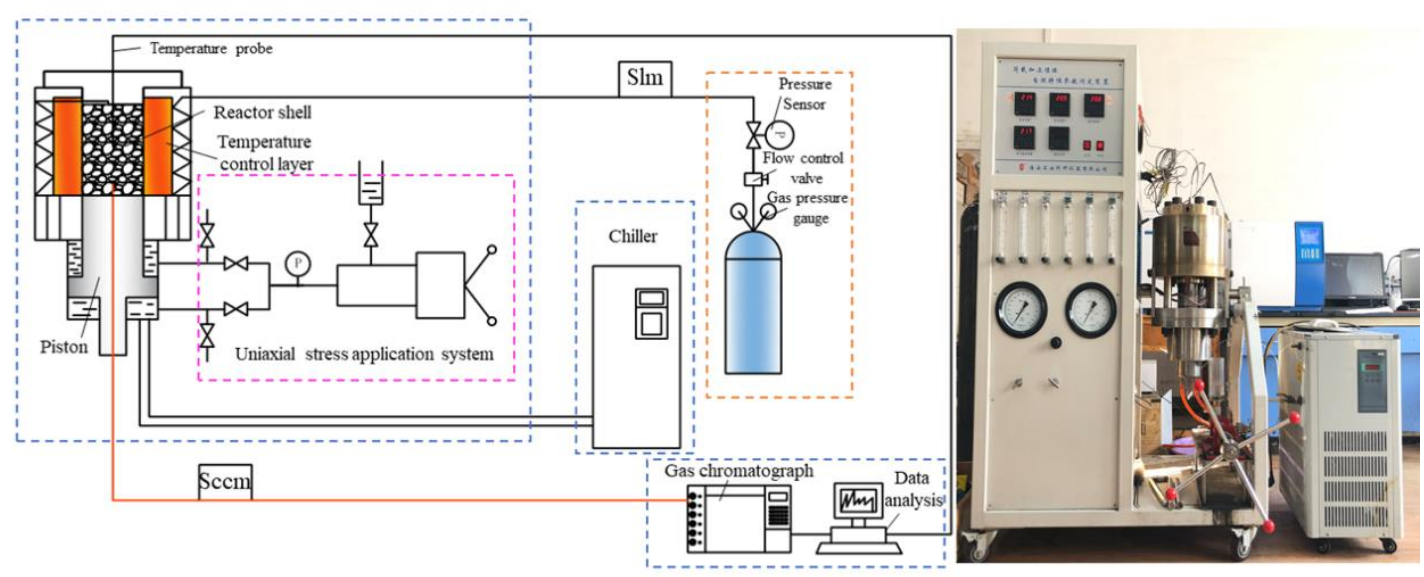

Fig.1 The UCTP experimental system and actual diagram.

\subsubsection{Fracture and pore structure analysis.}

The Scanning electron microscope (SEM) produced by Japan JEOL, model JSMIT500HR, was used to observe the morphological and structural changes of the pretreated coal sample. The natural cross-section of the central coal sample in the reactor under different uniaxial stresses was observed by scanning electron 
microscope, and the distribution characteristics of the meso-structure morphology at different positions of the sample were clearly presented. The coal sample was magnified 1000 times in a vacuum environment. In order to improve the conductivity, the coal sample was sprayed with gold.

\subsubsection{DSC and FTIR}

The thermal analysis experiment used STA449C synchronous thermal analyzer (NETZSCH company), the coal sample was taken from the inner center of the reactor, the mass is $20 \pm 0.1 \mathrm{mg}$, and the carrier gas was set in the air environment $\left(\left(\mathrm{V}\left(\mathrm{O}_{2}\right)\right.\right.$ : $\left.\left.V\left(N_{2}\right)\right)=1: 4\right)$. The total gas flow rate was $50 \mathrm{ml} \cdot \mathrm{min}^{-1}$, the heating rate was $10^{\circ} \mathrm{C} \cdot \mathrm{min}^{-}$ ${ }^{1}$, the start temperature of the test was $30{ }^{\circ} \mathrm{C}$, and the end temperature was $800{ }^{\circ} \mathrm{C}$. Using TENSOR-37 Fourier Transform Infrared Spectrometer (Bruker), the dried KBr and the coal sample in the center of the reactor were mixed according to the mass ratio of 100:1 and then pressed into tablets, and tested by infrared spectroscopy. The wave number ranged from $400-4000 \mathrm{~cm}^{-1}$, the resolution is $4 \mathrm{~cm}^{-1}$, and the cumulative number of scans was 32. The test result used the professional infrared analysis software OMNIC, the peak fitting method of Gaussian function, and the baseline was linear.

\section{Results and analyses}

\subsection{Micro structure}

The SEM results of 4 kinds of pretreated coal samples under uniaxial stress were obtained at a magnification of 1000 times, as shown in Fig.2.

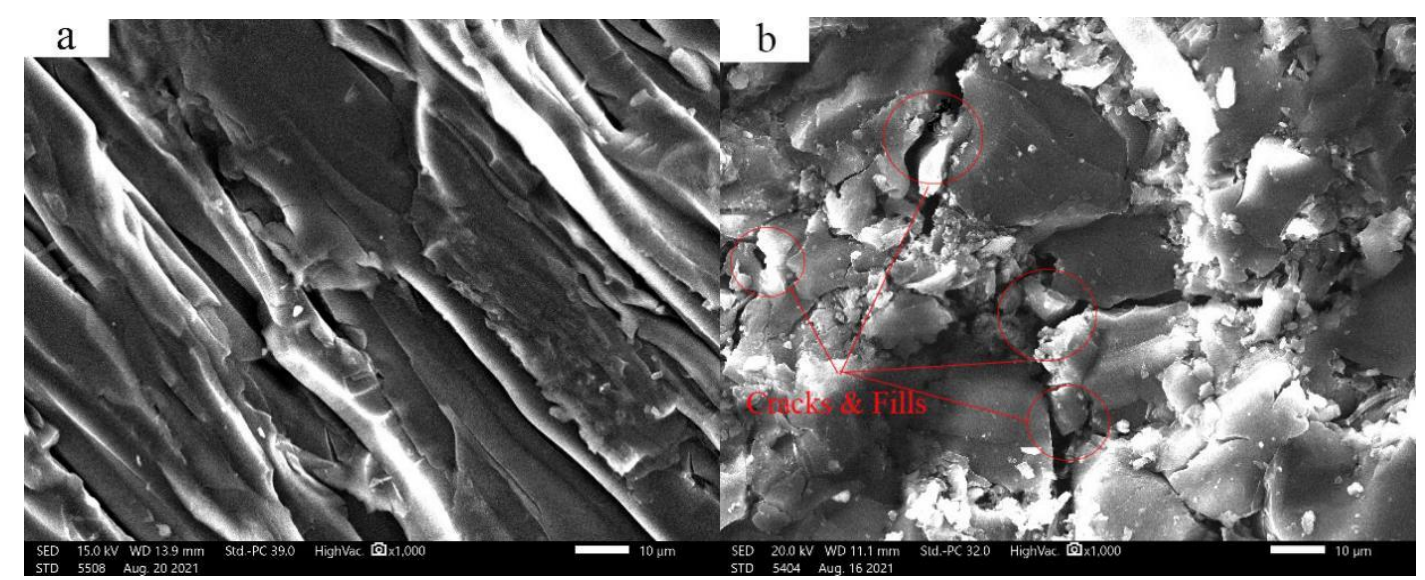




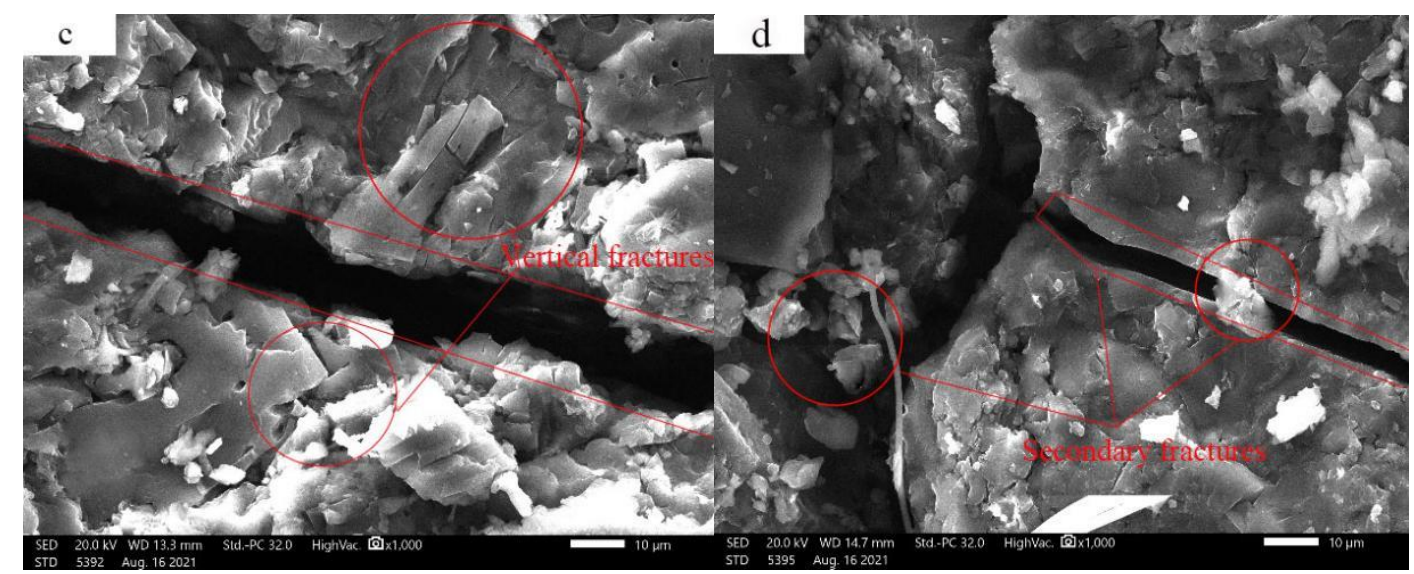

Fig. 2 SEM photo of coal sample pretreatment under uniaxial stress. (a) $0 \mathrm{MPa}$. (b) 2 MPa. (c) 4 $\mathrm{MPa}$ (d) $6 \mathrm{MPa}$.

The surface of the coal sample is relatively dense at $0 \mathrm{MPa}$, and the pore structure is very small. The coal is distributed in strips with a layered edge and no obvious fracture structure.

The coal sample under $2 \mathrm{MPa}$ has three obvious fractures, and the connectivity between the fractures is poor. They mostly exist on the unevenly distributed surface of the coal, and the fractures are stopped at the intersection of the fissures and the mineral particles. Obviously relaxed fractures appear at $4 \mathrm{MPa}$, there are fewer small particles of minerals and coal into the fractures, obvious vertical fractures appear on the surface, and obvious pore structures appear. At $6 \mathrm{MPa}$, there are more coal particles and mineral particles filled into the fractures, and it can also be found that these fillings have occurred secondary fractures, and the coal surface has an obvious lamella structure.

\subsection{Functional group content.}

In order to obtain the effect of uniaxial stress on the microstructure of coal, infrared spectroscopy experiments were carried out. The infrared spectrum of the pretreated coal sample in the center of the reactor is shown in Fig. 3(a), and the type and position of the absorption peak of each functional group are marked on the spectrum. Through the peak fitting method of Gaussian function, the relative content of each functional group is obtained according to the relatively stable $\mathrm{C}=\mathrm{C}$ functional group strength, as shown in Eq. (1)(Xu et al. 2020). Eqs. (2)-(4) obtain the 
deformation and porosity during the experiment, and Eq. (5) obtains the apparent activation energy $(\mathrm{Xu}$ et al. 2021). They reflect the different microstructure and spontaneous combustion tendency of coal.

$$
\begin{gathered}
W \%=\frac{A_{i}}{f} \div \frac{A_{C=C}}{f_{C=C}} \times 100 \\
\varepsilon=\frac{\Delta h}{h_{0}} \\
\varphi_{0}=\frac{\frac{1}{4} \pi d^{2} h_{0}-\frac{m}{\rho}}{\frac{1}{4} \pi d^{2} h_{0}} \\
\varphi=\frac{\frac{1}{4} \varphi_{0} \pi d^{2} h_{0}-\frac{1}{4} \pi d^{2} h_{0} \varepsilon}{\frac{1}{4} \pi d^{2}(1-\varepsilon) h_{0}}=\frac{\varphi_{0}-\varepsilon}{1-\varepsilon} \\
\ln \frac{C_{O_{2}}^{0}-C_{O_{2}}^{L}}{C_{O_{2}}^{L}}=-\frac{E_{a}}{R \theta}+\ln \left(\frac{V A_{0}}{Q}\right)
\end{gathered}
$$
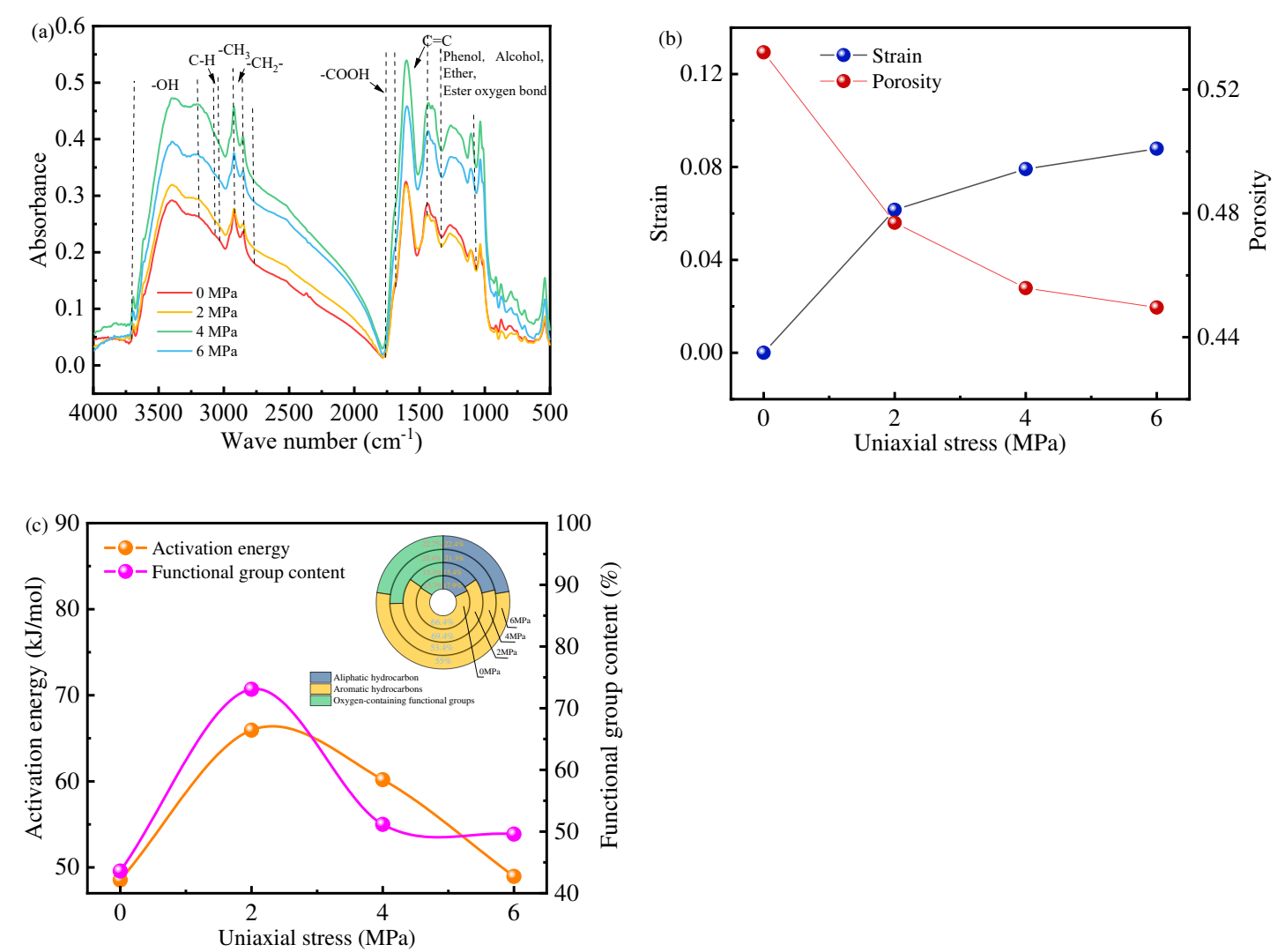

Fig .3 Microstructure changes under different uniaxial stresses. (a) Infrared spectra of preprocessed coal samples. (b) Stress-strain and stress-pore curves. (c) Changes in apparent activation energy and group content.

From the functional group spectrum of the coal sample after pretreatment in Fig. 3(a), it can be seen that under the influence of uniaxial stress, the relative content of $\mathrm{OH}$ shows a clear trend of first increasing and then decreasing. 
The content of $\mathrm{C}=\mathrm{C}$ and substituted benzene peaks in aromatic hydrocarbons is relatively high, but under nitrogen pretreatment with different uniaxial stresses, the content does not appear to change significantly with the uniaxial stress. Fig. 3(b) shows the relationship between strain and porosity of coal under uniaxial stress. With the increase of uniaxial stress, the strain of coal gradually increases, the growth rate of strain gradually declined, and the porosity is reversed. As the uniaxial stress continues to rise, due to the accumulation of stress energy and energy, the compressibility of the coal is changed, and new fractures are generated in the compacted crushed coal, resulting in a smaller deformation. It can be seen that in the coal structure, the uniaxial stress mainly changes the pore and fissure structure of the coal, resulting in the difference between the coal-oxygen reaction during the re-ignition. It shows that uniaxial stress mainly changes the fractures and pore structure of coal in the structure of coal body, and the pyrolysis process mainly changes the content and types of functional groups, both of which make coal exhibit different re-ignition characteristics. It can be seen from Fig. 3(c) that according to the relative content of different functional groups obtained in Fig. 3(a), aromatic hydrocarbons account for a large proportion. This is because when coal is pyrolyzed under uniaxial stress, liquid tar mainly composed of chain hydrocarbons and aromatic hydrocarbons and solid products mainly composed of semi-coke are mixed in the coal sample, which causes the aromatic hydrocarbon content in the FTIR test to be higher than that of the raw coal. However, the oxygen-containing functional groups $(-\mathrm{OH},-\mathrm{COOH}$, etc.) change significantly under different uniaxial stresses, which is the same result for the carboxyl and hydroxyl groups that directly affect the coal-oxygen reaction(Song et al. 2021).

In order to further analyze the relationship between coal re-ignition and microscopic groups under uniaxial stress, the relative content of hydroxyl and carboxyl groups was summed and compared with the apparent activation energy. Among them, the apparent activation energy can be obtained that $\ln \frac{C\left(\mathrm{O}_{2}\right)^{0}-\mathrm{C}\left(\mathrm{O}_{2}\right)}{C\left(\mathrm{O}_{2}\right)}$ and 
$\frac{1}{T}$ have a linear function relationship. After substituting the experimental data, the slope of the linear function, namely $-\frac{E_{a}}{R}$, can be obtained, and the apparent activation energy of the experimental coal samples under different uniaxial stresses can be obtained. As shown in Fig. 3(c), the higher the content of oxygen-containing functional groups, the greater the apparent activation energy, and the more difficult it is for the coal-oxygen reaction to occur. In addition, from the maximum value of the curve, the coal-oxygen reaction is the most difficult when the uniaxial stress is around 2.25 $\mathrm{MPa}$, and the possibility of re-ignition is the lowest when the fire zone is unsealed.

\subsection{Heating characteristics of coal samples.}

To investigate the heating characteristics broken coal after fire extinguishing by nitrogen injection, a heating experiment of broken coal in nitrogen atmosphere under uniaxial stress was carried out. Fig. 4 shows the changes in the heat transfer and thermal conductivity of the coal in the reactor during the uniaxial stress loading process. Since the coal does not undergo oxidation reaction, the thermal conductivity of the coal sample is estimated according to the law of conservation of energy $(\mathrm{Xu}$ et al. 2020), as shown in Eq. (6):

$$
\rho_{e} C_{e} \frac{\Delta T}{\Delta t}=\lambda \frac{T_{O V}-T}{\Delta x}
$$
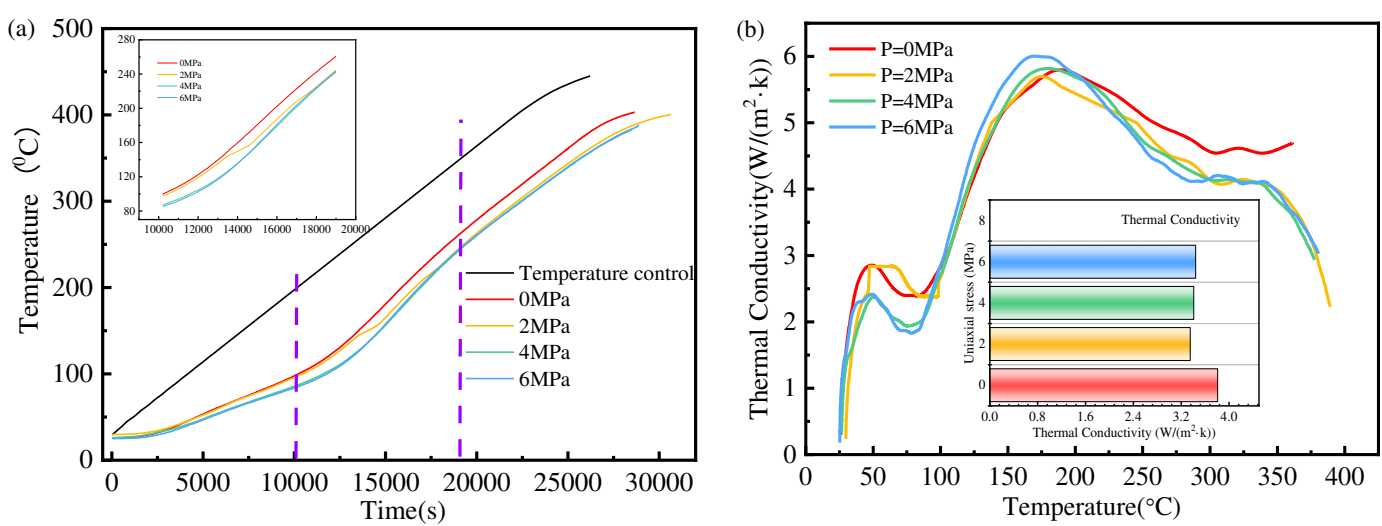

Fig. 4 Heat transfer and heating characteristics of coal in nitrogen atmosphere under different uniaxial stresses. (a) Heating curve. (b) Thermal conductivity.

It can be seen from Fig. 4 that the coal under nitrogen atmosphere does not have 
a cross temperature point during the heating process, and the core temperature of the coal under uniaxial stress is much lower than the temperature control. The main reason is that nitrogen inhibits the coal-oxygen reaction, reduces the heat of the chain reaction of the active groups, and the uniaxial stress fracturing coal produces fractures, which increases the contact thermal resistance. Therefore, the coal center temperature under uniaxial stress is relatively low. From Fig. 4(a), the heating trend of coal is the same when the uniaxial stress is $4 \mathrm{MPa}$ and $6 \mathrm{MPa}$, because the fractures and pore structures of the two coal samples are very similar after being broken under uniaxial stress at this time. When the uniaxial stress is $2 \mathrm{MPa}$, compared with other coal samples under uniaxial stress, the temperature rises faster before $13580 \mathrm{~s}$, because it is in the low temperature stage at this time, and more gas increases in the fractures and pore structure. The temperature drops after $13580 \mathrm{~s}$ because at this time, after the coal pyrolysis passes through the dehydration and degassing stage, the broken coal pyrolyzes, collapses, collides and frictions, resulting in unstable components such as semi-coke, and the heat transfer efficiency is reduced.

From Fig. 4(b), the thermal conductivity of coal under uniaxial stress shows periodic changes. $\lambda$ increases with the increase of temperature before $50{ }^{\circ} \mathrm{C}$, and decreases when the temperature reaches $50{ }^{\circ} \mathrm{C}-100{ }^{\circ} \mathrm{C}$. This is because at the initial stage of heating at $50^{\circ} \mathrm{C}-100^{\circ} \mathrm{C}$, the water in the coal sample evaporates, and the thermal conductivity of water is much higher than that of coal, so $\lambda$ decreases. $\lambda$ continues to increase after $100{ }^{\circ} \mathrm{C}$, and $\lambda$ decreases again at $170{ }^{\circ} \mathrm{C}$. This is because after $100^{\circ} \mathrm{C}$, the water evaporates completely, the activity of the active molecules in the coal macromolecular structure is enhanced, and the thermal conductivity increases rapidly. After $170{ }^{\circ} \mathrm{C}$, physical adsorption occurs on the coal surface, and a small amount of water vapor is found at the outlet of the airflow during the experiment. At this time, the thermal conductivity of water vapor is much smaller than that of coal, so the thermal conductivity begins to decrease again. Moreover, violent decomposition, depolymerization and decomposition reactions occur at this time, which leads to an 
increase in the temperature difference between the temperature of the coal sample and the furnace wall of the reactor, which reduces the thermal conductivity.

The average thermal conductivity of $0 \mathrm{MPa}$ is the highest, indicating that the uniaxial stress will reduce the thermal conductivity between the crushed coal particles. When the uniaxial stress is $2 \mathrm{MPa}-6 \mathrm{MPa}$, the average thermal conductivity decreases respectively by $0.459 \mathrm{~W} \cdot \mathrm{m}^{-2} \cdot \mathrm{K}^{-1}, 0.4 \mathrm{~W} \cdot \mathrm{m}^{-2} \cdot \mathrm{K}^{-1}, 0.368 \mathrm{~W} \cdot \mathrm{m}^{-2} \cdot \mathrm{K}^{-1}$, Which shows that the smaller the uniaxial stress, the more obvious the effect of hindering the heat transfer between the crushed coal. This is because with the increase of uniaxial stress, after the broken coal exceeds the compaction limit, the interaction produces secondary crushing and generates more fractures and pore structures. Meanwhile, under the influence of temperature, the formation of pyrolysis products will also indirectly affect the thermal conductivity.

\subsection{Re-ignition characteristic temperature and thermal effect.}

In order to explore the thermal effect in the process of coal re-ignition under different uniaxial stresses, the heat release, heat absorption and characteristic temperature points are analyzed, and the DSC curve is shown in Fig. 5. According to the change characteristics of the curve, the heat release process can be divided into three stages according to the initial heat release temperature $T_{1}$, the maximum heat release temperature $T_{2}$, and the end heat release temperature $T_{3}$. 


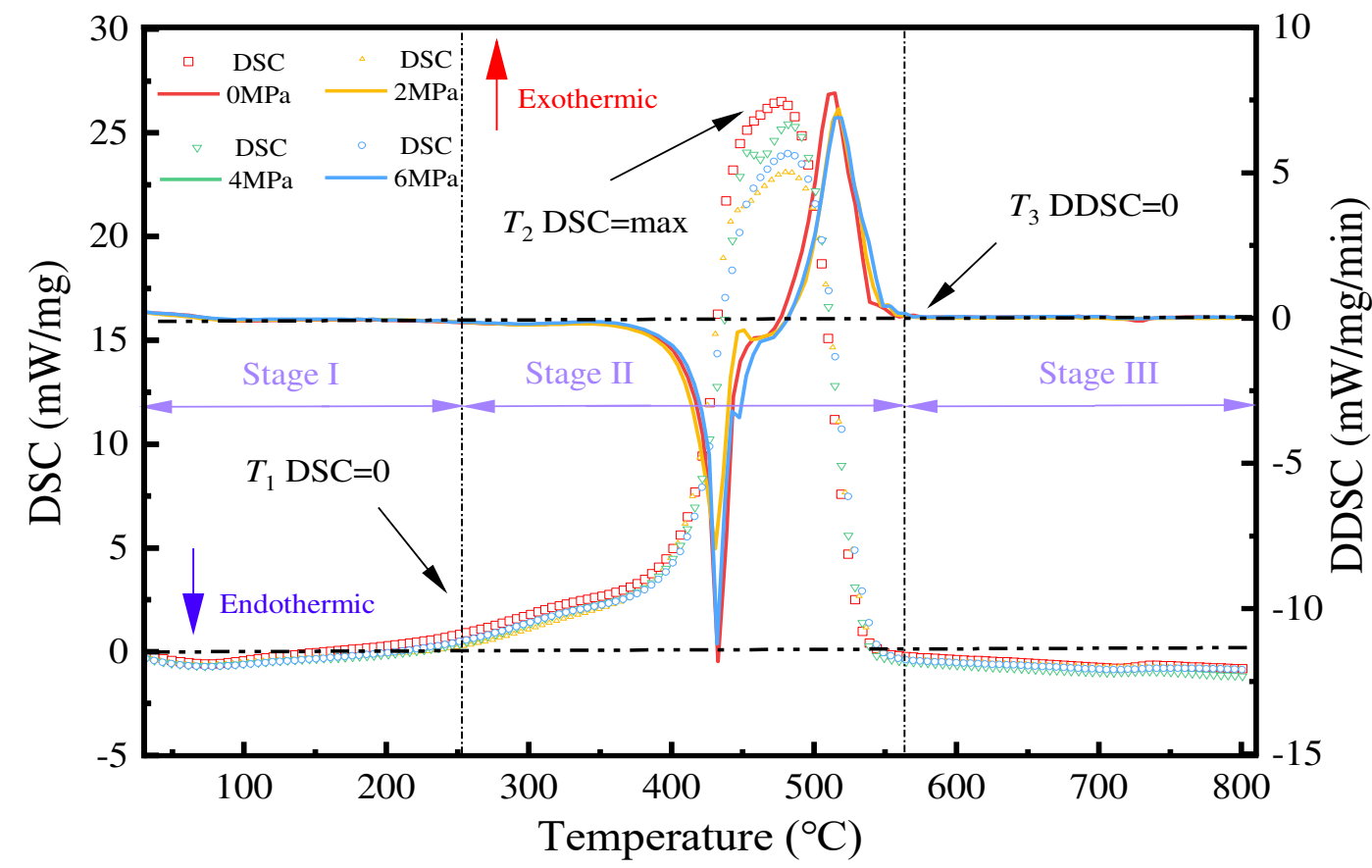

Fig. 5 DSC and DDSC curves of coal re-ignition under different uniaxial stresses.

\subsubsection{Re-ignition characteristic temperature analysis.}

Fig. 5 divides the re-ignition process into stages. From the beginning of the experiment to the low-temperature endothermic stage of coal (stage I) where T1 is coal, the heat absorbed by the evaporation of the original gas and moisture of the coal is greater than the heat released by the coal-oxygen reaction. $\mathrm{DSC}<0$, that is, stage I presents an endothermic state. In stage II $\left(\mathrm{T}_{1}-\mathrm{T}_{3}\right)$, the exothermic heat of the coaloxygen reaction is much greater than the endothermic heat. This stage presents an exothermic reaction, which is called the oxidation exothermic stage. When the temperature reaches $\mathrm{T}_{2}\left(\mathrm{DSC}_{\max }\right)$, the heat release reaches the maximum value. After the DSC curve reaches the maximum value, the coal is quickly consumed. Simultaneously, the DSC curve shows a rapid downward trend, and the coal-oxygen reaction rate drops rapidly. After the temperature reaches $\mathrm{T}_{3}(\mathrm{DDSC}=0)$, until the end of the experiment, the coal is consumed and enters the burnout phase, which is phase III. Table 2 shows the characteristic temperatures under different uniaxial stresses.

Table 2 Each characteristic temperature under different uniaxial stress.

\begin{tabular}{llll}
\hline Uniaxial stress $(\mathrm{MPa})$ & $\mathrm{T}_{1}\left({ }^{\circ} \mathrm{C}\right)$ & $\mathrm{T}_{2}\left({ }^{\circ} \mathrm{C}\right)$ & $\mathrm{T}_{3}\left({ }^{\circ} \mathrm{C}\right)$ \\
\hline
\end{tabular}




\begin{tabular}{llll}
\hline 0 & 161.01 & 476.86 & 542.28 \\
2 & 226.25 & 481.70 & 548.88 \\
4 & 211.23 & 480.83 & 544.08 \\
6 & 201.24 & 480.85 & 548.02 \\
\hline
\end{tabular}

From the DSC curve in Fig. 5, combined with the characteristic temperature points in Table 2, it can be seen that the curve changes show an increase with the uniaxial stress, and the coal re-ignition curve first moves to the high temperature zone and then gradually moves to the low temperature zone. This is because coal with a uniaxial stress of $2 \mathrm{MPa}$ is suppressed during the re-ignition process, which causes the curve to move to the high temperature zone and the characteristic temperature point rises. However, when the uniaxial stress exceeds $2 \mathrm{MPa}$, it shows a tendency to promote. It can be seen that although nitrogen injection and fire zone closure are effective means to control coal mine fires, when the fire zone is unsealed, the reignition characteristics of the residual coal under different uniaxial stress conditions are different.

It can also be seen from Fig. 5 that in the low-temperature endothermic stage I, there is no significant difference between the DSC curve and the DDSC curve of the coal sample under different uniaxial stresses. In stage II, the curve separation is larger. It can be further seen that the uniaxial stress has a significantly stronger influence on the exothermic stage than the low-temperature endothermic stage. This is because the change of heat flux in stage I mainly depends on the moisture evaporation phenomenon and gas desorption behavior in the coal that are susceptible to temperature, rather than the stress state of the coal. Further analysis of the coal reignition phenomenon, it can be seen that the uniaxial stress has a significantly stronger influence on the heat release stage of coal re-ignition than on the low temperature endothermic stage, and the characteristic temperature of the coal sample under uniaxial stress is higher. From Table 2, the characteristic temperature under different uniaxial stress is consistent with the heat flow curve, obviously. Compared with loose coal, $\mathrm{T}_{1}$ at a uniaxial stress of $2,4,6 \mathrm{MPa}$ is higher than $65.24{ }^{\circ} \mathrm{C}$, 
$50.22{ }^{\circ} \mathrm{C}$, and $40.23{ }^{\circ} \mathrm{C}$. $\mathrm{T}_{2}$ is $4.27{ }^{\circ} \mathrm{C}$ higher on average, while $\mathrm{T}_{3}$ is $0.4{ }^{\circ} \mathrm{C}, 5.2{ }^{\circ} \mathrm{C}$, and $1.26^{\circ} \mathrm{C}$ lower than loose coal. In stage III, it is mainly the pyrolysis and exotherm of residual minerals and ash. Based on the above analysis, it can be seen that uniaxial stress has a greater impact on the heat release stage of coal re-ignition.

\subsubsection{Thermal effect analysis.}

The equilibrium temperature is obtained through NETZSCH software analysis, and combined with the curve area, the heat change of the coal sample under different uniaxial stresses is obtained, as shown in Fig. 6.

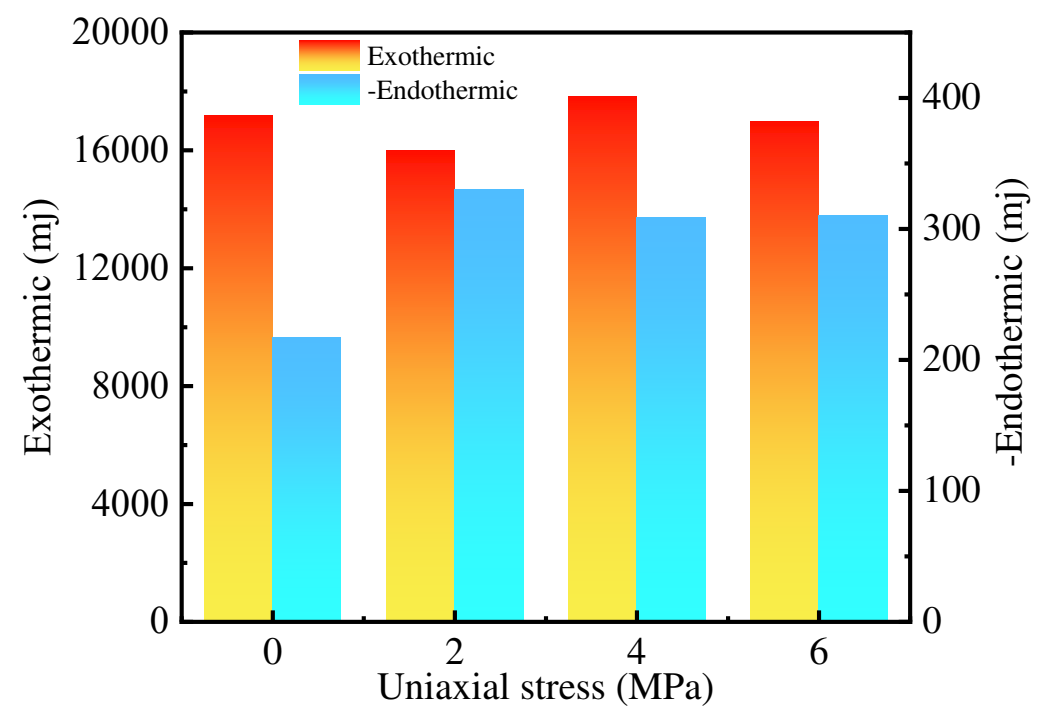

Fig. 6 Changes in heat release of coal re-ignition under different uniaxial stresses.

Fig. 6 shows the heat change of coal samples under different uniaxial stresses. The results show that with the increase of uniaxial stress, it shows a trend of first decreasing and then increasing. According to our previous research (Liu et al. 2021), compared with the heat release, nitrogen injection plays a key role in suppressing the spontaneous combustion of coal in the enclosed fire area. However, judging from the heat release of coal re-ignition under different uniaxial stresses, the heat generated during re-ignition of coal under uniaxial stress is quite different from the heat released by loose coal. The pressure-bearing coal pillars and residual coal should be intensively prevented and controlled when unsealing in the fire area.

In particular, relative to the coal sample of $0 \mathrm{MPa}$, when the uniaxial stress is 2 
$\mathrm{MPa}$ and $4 \mathrm{MPa}$, there is a significant decrease and increase, which proves that when $2 \mathrm{MPa}$ inhibits the oxidation exothermic process, the heat release is reduced by 1196 mJ. However, the heat release at $4 \mathrm{MPa}$ was significantly increased by $642 \mathrm{~mJ}$, which significantly promoted the heat release process of the coal-oxygen reaction. The heat release at $8 \mathrm{MPa}$ is reduced by $187 \mathrm{~mJ}$, and the lower heat release difference also indicates that the heat release characteristics of coal under higher uniaxial stress conditions are very close to that of loose coal. This means that even if the coal pillars and leftover coal with a high degree of compaction meet the oxygen in the air when the fire zone is unsealed, they still have the risk of re-ignition. This is also one of the reasons for the re-ignition after the fire zone has been closed, causing repeated spontaneous combustion of coal. Therefore, it is necessary to further study the reaction characteristics in the heat release stage of coal re-ignition under uniaxial stress.

\subsubsection{The relationship between characteristic temperature and}

\section{group content.}

From the DSC curve, $\mathrm{T}_{1}$ is the critical temperature of stage I and stage II. The low-temperature adsorption stage before $T_{1}$ determines the severity of the oxidation reaction after $T_{1}$. Moreover, the hydroxyl content in the oxygen-containing functional group has a greater impact on stage I. In order to further analyze the impact of the hydroxyl group on the re-ignition temperature point, the temperature $T_{1}$ and the hydroxyl content are compared and analyzed, as shown in Fig. 7. 


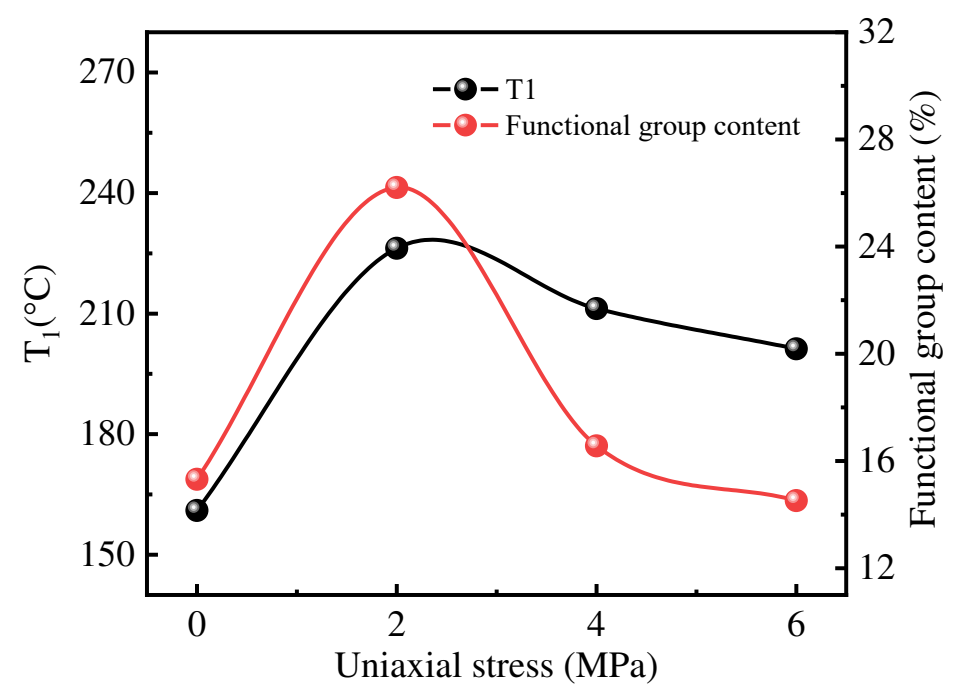

Fig. 7 The comparison curve of hydroxyl content and temperature $T_{1}$ under uniaxial stress.

It can be seen that when the uniaxial stress is $2 \mathrm{MPa}$, the low-temperature adsorption stage lasts the longest temperature stage. After $226.25{ }^{\circ} \mathrm{C}$, it stops endothermic and enters the oxidation exothermic stage. Similarly, it can be seen that the hydroxyl content of the coal sample under this uniaxial stress is the highest, reaching $26.20 \%$. On the one hand, because the coal sample under $2 \mathrm{MPa}$ has a higher degree of compaction after pretreatment with UCTP, oxygen flows more slowly in the fractures and pore structure of the coal during re-ignition, and the contact area between coal and oxygen is smaller. On the one hand, because the coal sample under $2 \mathrm{MPa}$ has a higher degree of compaction after pretreatment with UCTP, oxygen flows more slowly in the fractures and pore structure of the coal during re-ignition, and the contact area between coal and oxygen is smaller. As a result, the coal of 2 $\mathrm{MPa}$ begins to oxidize violently after the heat accumulation is high. On the other hand, because the final oxidation product of the hydroxyl group is water, its higher content will prolong the evaporation and desorption stage of water.

\subsection{Mechanism analysis.}

The morphology and structure of coal samples under different uniaxial stresses are shown in Fig. 8. The stress state will directly cause different changes to the fractures and pore structure of coal, thereby changing the active sites of coal-oxygen contact and changing the characteristics of re-ignition. As a result, the microscopic 
mechanism of coal re-ignition under uniaxial stress as shown in Fig. 9 is obtained. Coal is composed of condensed nucleated aromatic layers with branched chains and various functional groups. Under stress, part of the branched chains and functional groups are broken, and the macromolecular structure of coal changes (Dong et al. 2017). Moreover, during the pretreatment of the coal sample, the bond breakage caused by the thermal-stress coupling state and the bond breakage caused by the conversion of functional groups during re-ignition, the bond energy of the two together determine the exothermic change.

Among them, during the re-ignition process, $\mathrm{OH}$ can continue to undergo oxidation reactions during the exothermic stage of oxidation, continuously generating aliphatic hydrocarbons and oxygen-containing functional groups. The content of hydroxyl groups is different under different uniaxial stresses, resulting in different heat absorption and heat release of the coal-oxygen reaction. The $2 \mathrm{MPa}$ coal has the highest degree of compaction, which also causes a large number of hydroxyl groups to fail to fully react, and the heat release in stage II is low. Compared with loose coal, coal samples under uniaxial stress require higher re-ignition conditions, especially those with a uniaxial stress of $2 \mathrm{MPa}$. Compared with loose coal, coal samples under uniaxial stress require higher re-ignition conditions, especially those with a uniaxial stress of $2 \mathrm{MPa}$. However, the re-ignition characteristics of the coal sample with a uniaxial stress of $6 \mathrm{MPa}$ are very close to it. On the one hand, the number of pores and fractures are changed in the process of uniaxial stress rise, that is, the change that first decreases and then increases. The oxygen supply channel required for re-ignition was changed, resulting in significant changes in stage I and stage II. On the other hand, due to the different degree of coal pyrolysis under stress, the content of oxygencontaining functional groups changes. Therefore, before the fire zone is unsealed, the stress state of the residual coal is measured and a small amount of coal sample is taken for FTIR test, which can effectively prevent the risk of re-ignition when the fire zone is unsealed. 


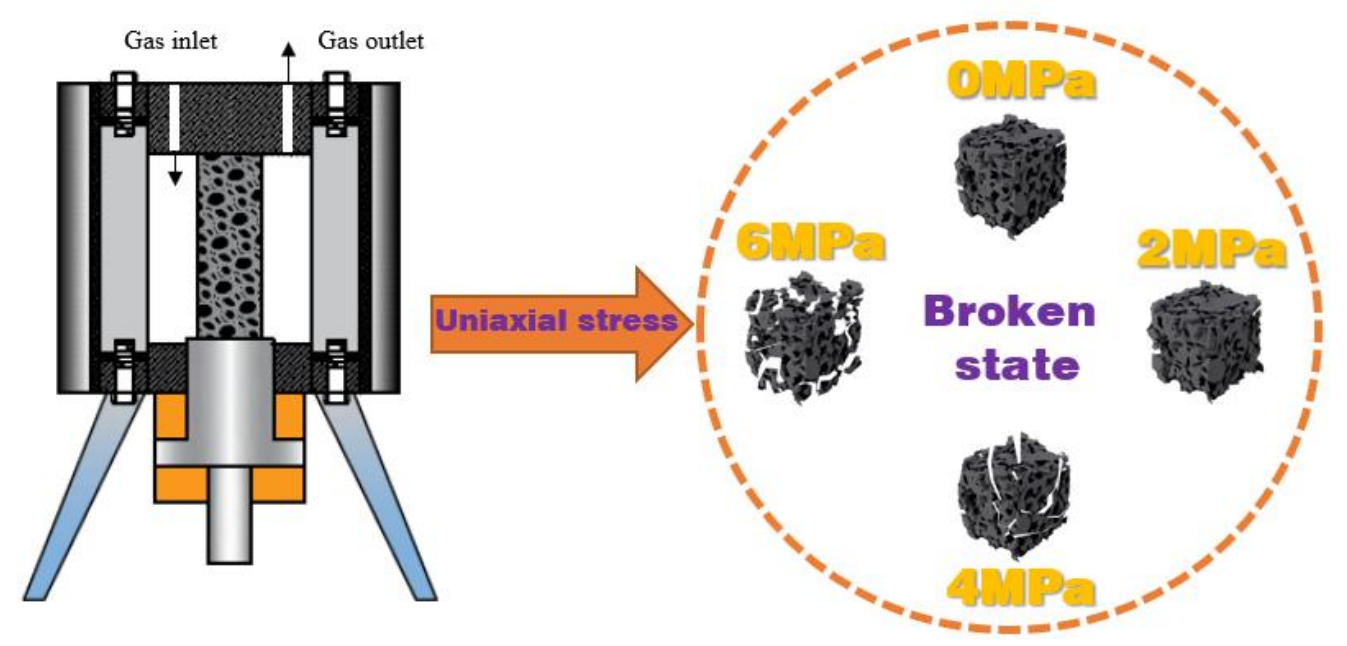

Fig. 8 The broken shape of broken coal under uniaxial stress.

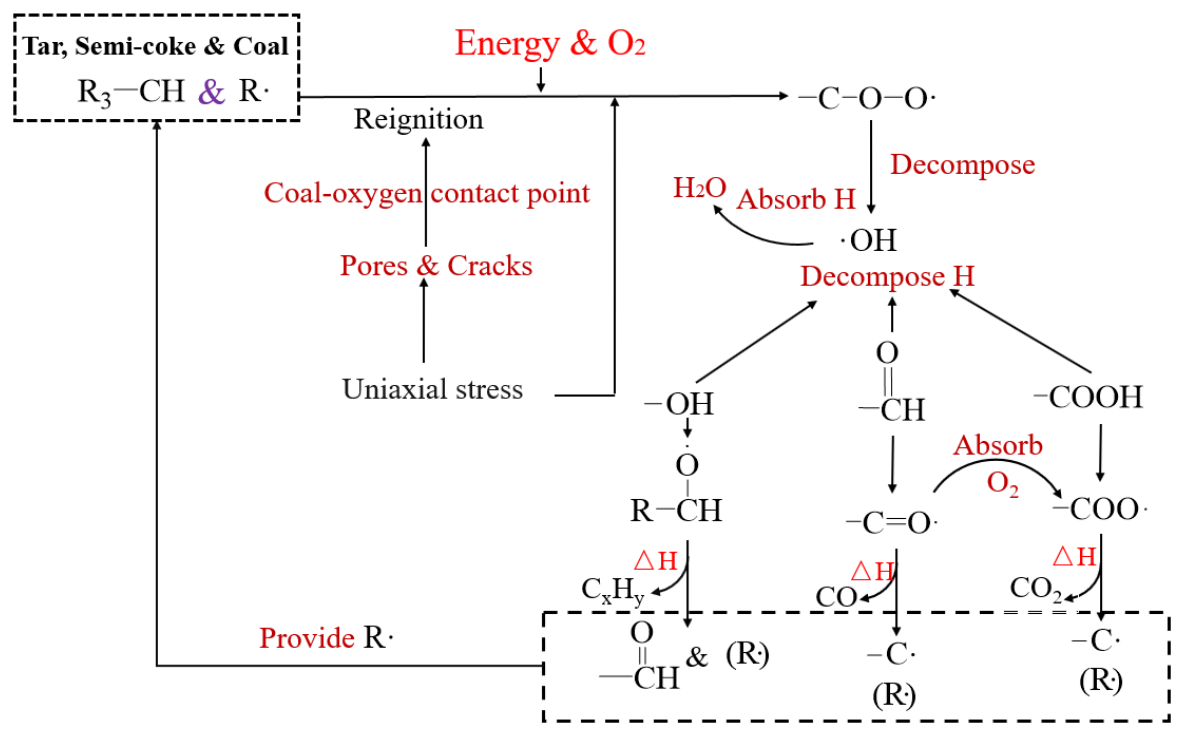

Fig. 9 Mechanism of coal re-ignition under uniaxial stress.

\section{Conclusions}

The re-ignition characteristics of coal samples under different uniaxial stresses are studied. Using UCTP device, SEM, thermal analysis and FTIR analysis, the effect of uniaxial stress on the fracture structure, functional groups and exothermic stage of the re-ignition of confined coal was studied. The structure evolution and resurgence mechanism of confined coal are proposed. The following conclusions are obtained:

(1) Uniaxial stress increases the diversity of cracks and pore structures and reduces the risk of coal re-ignition. Coal particles are rearranged, combined and filled under stress, and the rate of change of strain and porosity gradually decreases. The average 
thermal conductivity decreases first and then increases, while the apparent activation energy does the opposite. The content of oxygen in the fractures and pores is the main reason for changing the heat and mass transfer effect between coal particles.

(2) The oxidation exothermic stage of coal re-ignition oxidation becomes longer under stress, and the initial exothermic temperature and maximum heat release temperature first increase and then decrease. The heat and mass transfer efficiency of the coal sample before $2 \mathrm{MPa}$ was obviously suppressed, and then it showed a promoting effect. The thermal effect of the coal sample of $6 \mathrm{MPa}$ and the loose coal body showed very similar characteristics, and have a high tendency to re-ignition.

(3) The key group of the thermal characteristics of coal re-ignition is determined by the hydroxyl content, and mechanochemistry affects the difficulty of bond breaking. The bond energy and the coal-oxygen contact site determine the heat release of the reignition process.

\section{Acknowledgments}

The authors wish to acknowledge gratefully the financial support of the research funding provided by the National Natural Science Foundation of China (Nos.52074108 and 51874124), and the funding from the Scientific and Technological Research Projects in Henan Province (No.182102310771). It also supported by the Research Funds of Henan Polytechnic University (J2019-5). We also appreciate all the reviewers and editors for their professional and constructive comments.

\section{Author's contributions}

YX: Conceptualization, Funding acquisition, Writing - original draft. ZL: Experimental operation, Writing - original draft. XW: Experimental operation. LW: Conceptualization, Supervision, Funding acquisition. ZL: Experimental operation. JW: Experimental operation. ML: Experimental operation.

\section{Declarations}


Conflict of interest All the authors of this manuscript have approved the article's submission for publication, and there are no conflicts of interest to declare. This paper has not been published elsewhere and is not under consideration by another journal.

\section{Reference}

Plakunov MM, Yavuzturk CC, Chiasson AD (2020) On the effects of temperaturedependent diffusion of carbon dioxide from underground coal fires. Geothermics, 85:101768.

Zhou FB, Li JH, He S, Liu YS (2009) Experimental modeling study on the re-ignition phenomenon when opening a sealed fire zone. Procedia Earth and Planetary Science 1(1):161-168.

Xu YL, Liu ZJ, Wang LY, Lv ZG, Wu JD, Li MJ (2021) Hysteresis characteristics of oxidation-thermodynamic for residual coal in goaf under uniaxial stress. Fuel 306: 121750.

Shi GQ, Zhou T, Liu MX, Wang YM (2017) Numerical analysis on methane explosion hazard during the process of fire zong sealing in coal mine. J China Univ Min Technol 46(05): 997-1006.

Zhou XH, Li CY, Zhang LL, Song DP, Meng JL (2015) Numerical simulation of gas transport law in process of sealing fire zone. China J Geol Hazard Control, 26(02): 116-122.

Duan YL, Wang S, Wang WH, Zheng K (2020) Atmospheric disturbance on the gas explosion in closed fire zone. Int J Coal Sci Technol 7:752-765.

Duan YL, Wang S, Wang WH, Jiang XS, Li YB, Yang YL (2020) Analysis on influence of respiratory effect on oxygen concentration in closed fire zone of mine. J Safety Sci Technol 16(04):101-106.

Lu XX, Zhao HR, Zhu HQ, Han Y, Xue X (2018) Characteristic rule of spontaneous combustion tendency of oxidized coal at recrudescence stage. J China Coal Soc 43(10): 2809-2816.

Tan B, Zhu HQ, Wang HY, Xu JY, Zou J, Niu HY, Yang CY, Yu SJ (2014) Combustion state and surface temperature field evolution of closed firing zone in top-coal caving region of coal drift. J Cent South Univ 45(03):946-951.

Zhou FB, Li JH (2010) Prediction model for re-ignition of fire zone after unsealing based on BP neural networks. J Min Safety Eng 27(04): 494-498+504.

Cheng JW, Wang C, Zhang SS (2012) Methods to determine the mine gas explosibility - An overview. J Loss Prevent Proc 25(3): 425-435.

Cheng J, and Zhou F (2013) A systematic approach to assess mine atmospheric status. Fire Safety J 58: 142-150.

Zheng YN, Li QZ, Zhang GY, Zhao Y, Zhu PF, Ma X, Liu XX (2020) Effect of multicomponent gases competitive adsorption on coal spontaneous combustion characteristics under goaf conditions. Fuel Process Technol 208:106510.

Shang HB, Jin DW, Zhang TJ, Li SG, Wang ZZ, Zhao CH, Zhou ZF, Liu ZX (2019) 
Permeability evolution of broken coal under triaxial stress. J China Coal Soc 44(04):1066-1075.

Chao JK, Chu TX, Yu MG, Han XF, Hu DM, Liu W, Yang XL (2021) An experimental study on the oxidation kinetics characterization of broken coal under stress loading. Fuel 287:119515.

Hasan T, Gerhard JI, Hadden R, Rein G (2015) Self-sustaining smouldering combustion of coal tar for the remediation of contaminated sand: Twodimensional experiments and computational simulations. Fuel 150: 288-297.

Xu YL, Liu Y, Xie HL, Chen ML, Wang LY (2020) Experimental Study on Organic Sulfur Removal in Bituminous Coal by a 1-Carboxymethyl-3-methyl Imidazolium Bisulfate Ionic Liquid and Hydrogen Peroxide Solution. ACS OMEGA 5(33):21127-21136.

$\mathrm{Xu}$ YL, Liu ZJ, Bu YC, Chen ML, Lv ZG, Wang LY (2021) Catastrophic temperature of oxidation-spontaneous-combustion for bituminous coal under uniaxial stress. Chin J Eng 10:1312-1322.

Song HJ, Liu GR, Zhang JZ, Wu JH (2017) Pyrolysis characteristics and kinetics of low rank coals by TG-FTIR method. Fuel Process Techno 156:454-460.

Agarwal M, Kudapa VK, Sudharsan J (2021). Analytical study of structural characteristics of South Eastern coal field by FTIR spectroscopy and X-ray diffraction. Mater Today Proceed.

Xu YL, Zuo N, Bu YC, Wang LY. (2020) Experimental study on the characteristics of oxidation kinetics and heat transfer for coal-field fires under axial compression. $\mathrm{J}$ Therm Anal Calorim 139(1):597-607.

Liu ZJ, Xu YL, Wen XL, Lv ZG, Wu JD, Li MJ, Wang LY (2021) Thermal Properties and Key Groups Evolution of Low-Temperature Oxidation for Bituminous Coal under Lean-Oxygen Environment. ACS Omega 6:15115-15125

Dong YJ, Han YZ, Hou QL, Wang J (2017) Mechanochemistry mechanism of gas generation during coal deformation. J China Coal Soc 42(04):942-949. 